\title{
Journal of Engineering
}

journal homepage: www.joe.uobaghdad.edu.iq

Number 11 Volume 24 November 2018

\section{Chemical, Petroleum and Environmental Engineering}

\section{Deep Oxidative Desulfurization of Model fuels by Prepared $\mathrm{Nano}^{\mathrm{TiO}_{2}}$ with Phosphotungstic acid}

\author{
Basma Abbas Abdulmajeed \\ Chemical Eng. Dept. \\ College of Engineering \\ Baghdad - Iraq \\ basma1957@yahoo.com
}

\author{
Sameera Hamadullah* \\ Petroleum Eng. Dept. \\ College of Engineering \\ Baghdad - Iraq \\ sameerahamdulla@yahoo.com
}

\author{
Fadhil Abed Allawi \\ Chemical Eng. Dept. \\ College of Engineering \\ Baghdad - Iraq \\ fadel-eng2009@yahoo.com
}

\begin{abstract}
In this study, nano $\mathrm{TiO}_{2}$ was prepared with titanium isopropoxide (TTIP) as a resource to titanium oxide. The catalyst was synthesized using phosphotungstic acid (PTA) and, stearyl trimethyl ammonium bromide (STAB) was used as the structure-directing material. Characterization of the product was done by the X-ray diffraction (XRD), X-ray fluorescent spectroscopy (XRF), nitrogen adsorption/desorption measurements, Atomic Force Microscope (AFM) and Fourier transform infrared (FTIR) spectra, were used to characterize the calcined $\mathrm{TiO}_{2}$ nanoparticles by STAB and PWA. The $\mathrm{TiO}_{2}$ nanomaterials were prepared in three crystalline forms (amorphous, anatase, anatase-rutile). The results showed that the nanoparticles of anatase $\mathrm{TiO}_{2}$ have good catalytic oxidative activity. This is because of the conversions of $100 \%$ within $90 \mathrm{sec}$ from $300 \mathrm{ppm}$ of dibenzothiophene. This is compared to conversion rates for anatase-rutile nanoparticles and amorphous nanoparticles which reached $52 \%$ and $31 \%$, respectively. The influence of the temperature of reaction, catalyst amount, $\mathrm{H}_{2} \mathrm{O}_{2}$ concentration, and initial DBT concentration on the oxidation of DBT was investigated.
\end{abstract}

Keywords: Oxidative desulfurization, Nanoparticles of $\mathrm{TiO}_{2}$, liquid-liquid-solid system

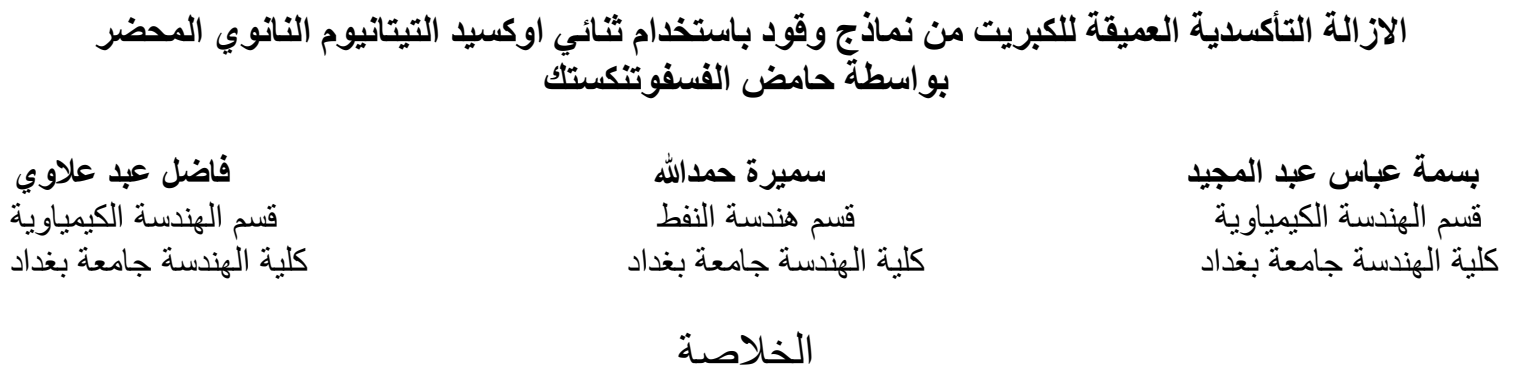

في هذه الدر اسة تم تحضير ثنائي اوكسيد التيتانيوم النانوي عن طريق استخدام تيتانيوم تتر ا- ايسوبروبو اوكسايد كمادة اولية

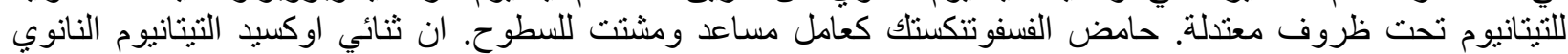

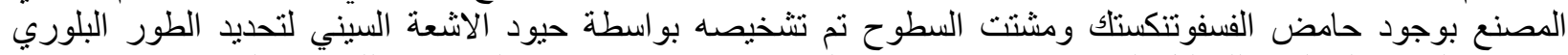

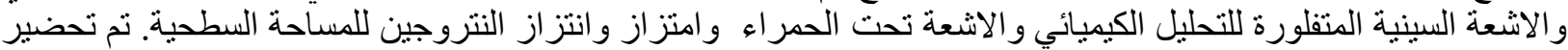

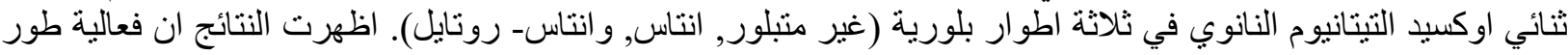

\section{*Corresponding author}

Peer review under the responsibility of University of Baghdad.

https://doi.org/10.31026/j.eng.2018.11.04

2520-3339 ( 2018 University of Baghdad. Production and hosting by Journal of Engineering.

This is an open access article under the CC BY-NC license (http://creativecommons.org/licenses/by-nc/4.0/)

Article received: 3/6/2017

Article accepted: 17/12/2017 


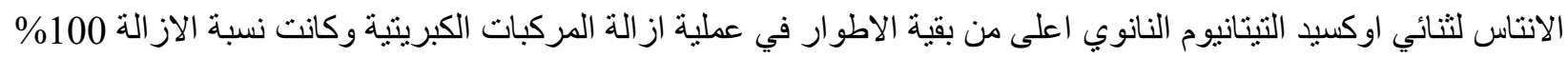

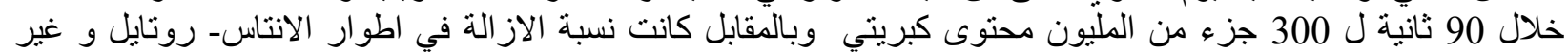

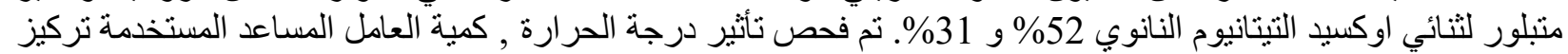

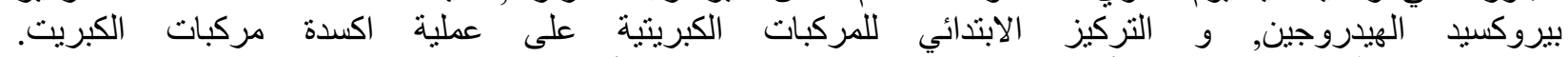
الكلمات الرئيسية: ازالة الكبريت التأكسدية, ثنائي اوكسيد التيتانيوم النانوي, أنظمة السائلسئسائل-صلب

\section{INTRODUCTION}

The process of deep desulfurization of fuel has been known around the world. This is because of the air that is polluted by the oxides of sulfur. Strict regulations were recently put by governments around to protect the environment, with an increase to develop deep desulfurization technologies, Yazu, et al., 2001.

Hydro-desulfurization (HDS) is used to get rid of the compounds of sulfur. It needs high values of temperature and pressure to be completed. Some sulfur compounds, like dibenzothiophene (DBT) and 4,6-dimethyl dibenzothiophene (4,6-DMDBT), cannot be easily removed using this method. HDS needs long times of residence so the compounds of sulfur are removed, so the method is difficult to be accomplished and may cause a significant decrease in octane number and increased consumption of hydrogen. So, HDS may lead to high cost, Babich, and Moulijin, 2003.

To increase the activity and efficiency of desulfurization, suitable catalysts are needed, Lorencon, et al., 2014. Investigation and studied, catalysts of titanium and used in the process of oxidative desulfurization (ODS). These catalysts gave good performance in the system of ODS. This is because of producing active radical lead to interaction between the sites of Ti (IV) and $\mathrm{H}_{2} \mathrm{O}_{2}$. The materials that contain Ti were cheap and free of pollution, Jin, et al., 2008, Kong, et al., 2004. Titanium silicalite (TS), e.g. micro/mesoporous TS-1 Jin, et al., 2008, investigated the sulfur removal considering $\mathrm{TiO}_{2} / \mathrm{SiO}_{2}$ ratio hexagonal mesoporous molecular sieves containing Ti (Ti-HMS), Zhao, et al., 2007 and hierarchical TS-1, Lv, et al., 2014 have gained a lot of attention. Also, titanium dioxide $\left(\mathrm{TiO}_{2}\right)$ has been widely investigated. Many workers have studied $\mathrm{TiO}_{2}$ as a carrier or in nanotube morphology, Zhang, et al., 2014, Meman, et al., 2014. Several researchers have studied oxidative desulfurization with $\mathrm{Ti}$ or $\mathrm{TiO}_{2}$ materials, Lorencon, et al., 2014, Cui, and wang, 2007, Shen, et al., 2015. That $\mathrm{V}_{2} \mathrm{O}_{5}$ located in $\mathrm{TiO}_{2}$ as a catalyst exhibits good desulfurization properties Ramos, and Cedeno, 2011. That Lewis acidic sites are very important for removing sulfur oxidants and synthesized $\mathrm{TiO}_{2}$ with phosphotungstic acid (PTA) as a catalyst for ODS; results showed that DBT conversion as high as $95.2 \%$ may be obtained with increasing $\mathrm{TiO}_{2}$, Yan, et al., 2013. $\mathrm{Fe}-\mathrm{TiO}_{2}$ as a catalyst in desulfurization and found that $300 \mathrm{ppm}$ of DBT can be removed at $\mathrm{pH} 0$ and $10 \mathrm{wt} \% \mathrm{Fe}$ by $\mathrm{Fe}-\mathrm{TiO}_{2}$; the authors also revealed that $\mathrm{Fe}$ and $\mathrm{Ti}$ function as active sites in this reaction, Arellano, et al., 2014. Mesoporous TS-1 synthesized through $\mathrm{SiO}_{2}-\mathrm{TiO}_{2}$ can remove $96 \%$ of the DBT in oil within $2 \mathrm{~h}$, Yang, et al., 2012.

In the present work, the $\mathrm{TiO}_{2}$ catalyst has been synthesized and used in the system of ODS. The preparation of $\mathrm{TiO}_{2}$ is done using titanium isopropoxide. The effect of the temperature of calcination in addition to the various parameters of the reaction is to be evaluated in the model oil desulfurization. 


\section{METHODS AND EXPERIMENTS}

\subsection{Materials}

Analytical grade purity reagents were used and did not need purification; tetra-isopropoxide (TTIP) with a purity of $97 \%$. Ti $\left[\mathrm{OC}_{3} \mathrm{H}_{7}\right]_{4}$ is used as a starting material (Sigma-Aldrich company). Stearyl trimethylammonium bromide (STAB), hydrogen peroxide $\left(\mathrm{H}_{2} \mathrm{O}_{2}\right)$ with $30 \%$ aqueous solution, n-octane (chemically pure) and phosphotungstic acid (PTA) were supplied by (High Media). Ethanol was supplied by Sigma-Aldrich Company. To prepare all standard solutions, De-ionized water was used.

\subsection{Preparation of tio2 Nanoparticles}

In this work, the solution of the precursor was a mixture of titanium tetra-isopropoxide TTIP (97\%), and quaternary ammonium bromide was dissolved in the absolute ethanol. A weight ratio of $1 / 7$ was used with stirring. The solution of PWA with the concentration of $0.15 \mathrm{M}$ was added. Then, stirring of the resulted suspension was done for two hours. The mixing was done at room temperature. $20 \mathrm{ml}$ of deionized water was then added in a dropwise manner. An additional 1 hour stirring of the solution was done. Then, a rotatory evaporator was followed to accomplish the evaporation. The washing of the resulted solid product was done using deionized water and ethanol many times. Then it was dried in vacuum at $80^{\circ} \mathrm{C}$ overnight. Then calcination was done at $500^{\circ} \mathrm{C}$ for 2 hours, Huang, et al., 2006.

\subsection{Characaterization of tion Nanoparticles}

$\mathrm{X}$-ray diffraction (XRD) with a Rigaku D/max-RB diffractometer in reflection mode using $\mathrm{Cu}$ Ka radiation was used. A voltage of $40 \mathrm{kV}$ was used to find the composition of the crystal phase and the size of the crystallite. (FTIR) was applied using (IR-Affinity, Shimadzu, Japan) with wave range between (400-4000) $\mathrm{cm}^{-1}$. The specific surface area (BET) was determined by using Brunauer, Emmett, and Teller (BET) method with Thermo Analyzer/USA. The average particle size of each sample (different crystalline form) was tested using Atomic Force Microscope Device (type Angstrom, Scanning Probe Microscope, Advanced Inc, AA 3000, USA)

\subsection{Oxidative Desulfurization}

The model fuel was made by dissolving DBT in octane solution. A $150 \mathrm{~mL}$ glass- reactor with a stirrer was used. A water bath was used with the reactor to maintain a stable temperature of the reaction. A magnetic stirrer with $800 \mathrm{rpm}$ was used. The model fuel and the prepared catalyst were added to the reactor, where preheating is accomplished for $5 \mathrm{~min}$. Then, $\mathrm{H}_{2} \mathrm{O}_{2}$ was added to the reactor so that the reaction is initiated. At different times, the samples were collected. They are centrifuged and then analyzed by U-V spectroscopy. Studying the effects of different crystalline forms(amorphous, anatase, and anatase-rutile), stirring rate(200 to $1200 \mathrm{rpm}$ ), reaction temperature $\left(40\right.$ to $\left.70^{\circ} \mathrm{C}\right)$, catalyst amount $(0.1$ to $0.5 \mathrm{gm})$, oxidant content $(5: 1$ to $20: 1 \mathrm{~mol}$ ratio $\mathrm{H}_{2} \mathrm{O}_{2}$ :DBT) and initial DBT concentration(300 to $\left.3000 \mathrm{ppm}\right)$ on the removal of sulfur compounds from model fuels. 


\section{RESULTS AND DISCUSSION \\ 3.1 Characterization of the $\mathrm{TiO}_{2}$ Nanoparticles}

The patterns of XRD show that different forms of nanoparticles of $\mathrm{TiO}_{2}$ can be produced by different calcination temperatures. Fig.1 shows a sharp peak at $2 \Theta=25.2$. This is the main peak for the nanoparticles of $\mathrm{TiO}_{2}$ that are calcinated at $500^{\circ} \mathrm{C}$. Anatase form is obtained, and the peak of $2 \Theta$ is comparatively broad due to the nanosize of crystals.

The pattern of XRD for nano- $\mathrm{TiO}_{2}$ that is calcined at $700^{\circ} \mathrm{C}$ agrees with the pattern of anataserutile to a great degree. The $\mathrm{XRD}$ pattern of nano- $\mathrm{TiO}_{2}$ that is calcinated at $120^{\circ} \mathrm{C}$ shows an amorphous structure. The results of BET for amorphous, anatase, and anatase-rutile $\mathrm{TiO}_{2}$ are given in Table 1. The result of (AFM) showed that the average particles size of the anatase phase was (77.92) $\mathrm{nm}$ and for anatase-rutile phase (96) $\mathrm{nm}$. The value of the surface area of amorphous $\mathrm{TiO}_{2}$ is $1183 \mathrm{~m}^{2} / \mathrm{g}$. It is much bigger than that of anatase form and anatase-rutile form of $\mathrm{TiO}_{2}$. Their surface areas are 423.5 and $284.2 \mathrm{~m}^{2} / \mathrm{g}$, respectively. The total pore volume of amorphous $\mathrm{TiO}_{2}$ is almost $0.51 \mathrm{~cm}^{3} / \mathrm{g}$. The total pore volumes of the anatase form of $\mathrm{TiO}_{2}$ and anatase-rutile form of $\mathrm{TiO}_{2}$ are about 0.456 and $0.12 \mathrm{~cm}^{3} / \mathrm{g}$, respectively.

The contents of $\mathrm{Ti}, \mathrm{W}, \mathrm{O}, \mathrm{P}$, and others inside the calcined $\mathrm{TiO}_{2}$ were measured using XRF. The results are shown in Table 2. Both the tungsten and phosphorus were detected. Neither nitrogen $(\mathrm{N})$ nor bromine $(\mathrm{Br})$ was found. So, this proves that there I no STAB in the calcined $\mathrm{TiO}_{2}$. This suggests that a small quantity of STAB is found in the calcined material. STAB was removed during the process of calcination to a large extent. This led to pore size and volume of large value.

Comparing the structure of $\mathrm{TiO}_{2}$ forms with or without STAB was done. The results of surface area (BET), average pore size, and the total pore volume are given in Table 3 . Different interactions between the surfactant and the precursor of titania exist. These include electrostatic, van der Waals interactions, and hydrogen bonding. This is in the case of STAB-paths and apart from the bonds of hydrogen that exist between both PTA and titanium tetra-isopropoxide. When these interactions are balanced to a good extent, there will be a self-assembly mechanism. This will give a wide range of forms and textural properties. STAB performs as the material that directs the structure. Calcination was used to successfully remove STAB. This will lead to a larger pore volume and size. The total pore volumes were from 0.278 to $0.456 \mathrm{~cm}^{3} / \mathrm{g}$. The $\mathrm{TiO}_{2}$ forms using STAB have a greater surface area of $423.5 \mathrm{~m}^{2} / \mathrm{g}$ compared to $312 \mathrm{~m}^{2} / \mathrm{g}$ for the anatase phase.

The FTIR spectrum confirmed the structure of $\mathrm{TiO}_{2}$. No special band of PTA was seen in the $\mathrm{TiO}_{2}$. This could mean that there is no sign of PTA crystals in $\mathrm{TiO}_{2}$ forms. The FTIR spectra recorded for the calcined $\mathrm{TiO}_{2}$ materials with STAB, given in Fig. 2, showing more information about the $\mathrm{TiO}_{2}$ structure.

\subsection{Effect of the $\mathrm{TiO}_{2}$ Crystalline Form on DBT Oxidation}

To ensure the removal of the sulfur compounds in the model fuels, three types of $\mathrm{TiO}_{2}$ were used as the catalysts oxidation. When adding $\mathrm{H}_{2} \mathrm{O}_{2}$ to the model fuels a faint yellow product is generated. This is adsorbed on the surface of the catalyst. This result is in agreement consistent with that of Yang, et al., 2007. The resultant $\mathrm{TiO}_{2}$ has different properties since the experiments showed that different $\mathrm{TiO}_{2}$ forms have different effects. In Fig. 3, the experimental results of the catalysts of nano- $\mathrm{TiO}_{2}$ anatase, nano- $\mathrm{TiO}_{2}$ anatase-rutile, and nano- $\mathrm{TiO}_{2}$ amorphous which were used as catalysts in oxidative desulfurization are shown.

Nano- $\mathrm{TiO}_{2}$ of anatase form showed a high value of activity for the process of catalytic oxidation of DBT. DBT conversion of as high as $100 \%$ was reached at a time of reaction of $90 \mathrm{sec}$. The 
catalytic rates presented by anatase- rutile $\mathrm{TiO}_{2}$ and amorphous $\mathrm{TiO}_{2}$ were only $52 \%$ and $31.7 \%$, respectively.

\subsection{Effect of Stirring Rate on Conversion}

Fig. 4 shows the effect of stirring rate on the DBT conversion. At $300 \mathrm{rpm}$ rate of stirring, the rate of reaction was slow giving a DBT conversion of only about $44 \%$ at $120 \mathrm{sec}$. As the rate of stirring is increased to $500 \mathrm{rpm}$, the rate of reaction was enhanced. Under this condition, the rate of conversion of more than $70 \%$ was obtained at a time of $120 \mathrm{sec}$. The rate of the reaction showed no further increase beyond this stirring rate. In fact, higher rates of stirring will decrease the resistance to external diffusion. So, the rate of stirring is fixed at $800 \mathrm{rpm}$ in other experiments.

\subsection{Effect of Temperature on DBT Oxidation}

Temperature is one of the important factors that affect any reaction. The effect of temperature on the oxidation of DBT was investigated and shown in Fig. 5. The conversion of DBT can be enhanced as the temperature of reaction increases from 40 to $70^{\circ} \mathrm{C}$. DBT conversion was about $43.5 \%$ at the reaction temperature of $40^{\circ} \mathrm{C}$. DBT may be completely removed within a time of 90 $\mathrm{sec}$ as the temperature increased to $70^{\circ} \mathrm{C}$. Therefore, temperatures of high value are necessary for the reaction.

\subsection{Effect of the Initial Concentration on the Conversion}

The initial concentration of sulfur compounds is important. This concentration can define what is application range of catalyst. As shown in Fig. 6, the initial DBT concentration increased with decreasing the DBT conversion. It can be seen that when the initial DBT concentration was 300 ppm, the conversion of DBT was highest. When the sulfur concentration initially equals 600 ppm, the conversion is less than that at $300 \mathrm{ppm}$. The lowest rate of conversion was found at an initial concentration of $3000 \mathrm{ppm}$. As a result, $\mathrm{TiO}_{2}$ can be used in the deep oxidative desulfurization.

\subsection{Effect of Catalyst Amount of Conversion}

Fig. 7 shows the effect of the amount of catalyst on the conversion of DBT. The conversion was enhanced with the increase in the amount of catalyst from $0.1 \mathrm{~g}$ to $0.3 \mathrm{~g}$. The rate of reaction could not be enhanced when the amount of catalyst increased from $0.3 \mathrm{~g}$ to $0.4 \mathrm{~g}$. This could be because excess $\mathrm{TiO}_{2}$ causes an ease of agglomeration in the system of reaction. This reduces the active sites of $\mathrm{TiO}_{2}$.

\subsection{Effect of Oxidant Amount on Conversion}

The amount of oxidant largely affects the reaction. Fig. 8 shows the effect of the amount of oxidant on the rate of conversion of DBT. It could be seen that the reaction rate is enhanced at first and then decreased when the molar ratio of $\mathrm{H}_{2} \mathrm{O}_{2}$ to DBT increased from 5:1 to 20:1. As the ratio decreased to a value less than 10, the rate of reaction becomes low. As the $\mathrm{H}_{2} \mathrm{O}_{2}$ amount is increased, the reaction rate significantly increased. However, more increase in $\mathrm{H}_{2} \mathrm{O}_{2}$ reduced the rate of reaction. 


\section{Number 11 Volume 24 November 2018 Journal of Engineering}

This may be attributed to: increases in $\mathrm{H}_{2} \mathrm{O}_{2}$ give more oxygen radicals and so oxidization of the DBT happens. So the reaction is promoted. In increasing the amount of $\mathrm{H}_{2} \mathrm{O}_{2}$ to a certain level, a liquid film on $\mathrm{TiO}_{2}$ may form by adding more $\mathrm{H}_{2} \mathrm{O}_{2}$. This affects the adsorption of DBT on active sites. By this and under high $\mathrm{H}_{2} \mathrm{O}_{2}$ content, the reaction is limited.

\section{CONCLUSIONS}

$\mathrm{TiO}_{2}$ nanomaterials with different forms were successfully prepared using a catalyst of PTA and octadecyl trimethyl ammonium bromide (STAB) as the agent that directs the structure. XRF results show that small amount of STAB existed in the calcined forms. During the calcination, STAB was removed to a great extent. This will lead to the larger value of pore volume and size. The results in the reaction system indicate that nano- $\mathrm{TiO}_{2}$ of anatase form is more selective than anatase-rutile nano- $\mathrm{TiO}_{2}$ form and of amorphous nano- $\mathrm{TiO}_{2}$. The complete DBT (300 ppm) conversion in experiments is obtained within $90 \mathrm{~s}$ with nano- $\mathrm{TiO}_{2}$ of anatase form as the catalyst. When the stirring rate was above $600 \mathrm{rpm}$, it has little effect on the reaction. As the temperature increases from $40^{\circ} \mathrm{C}$ to $70^{\circ} \mathrm{C}$, the reaction rate is greatly increased. Different initial concentrations of DBT were studied. Their results showed that the rate of reaction increases with the increase in the initial concentration of DBT. An inadequate amount of the catalyst is not good for the reaction. The results showed that $0.3 \mathrm{~g}$ of $\mathrm{TiO}_{2}$ gives the best rate of reaction. The optimum molar ratio of $\mathrm{H}_{2} \mathrm{O}_{2}$ to sulfide is $10: 1$.

As a conclusion, anatase nanoparticles of $\mathrm{TiO}_{2}$ are a favorable catalyst for the process of direct deep oxidative desulfurization. Tungeston element in $\mathrm{TiO}_{2}$ represents the active site for the oxidation reaction of DBT. In the presence of hydrogen peroxide, peroxide of $\mathrm{W}^{6+}$ is formed. It moreover reacts with the compounds of sulfur. This is done by the insertion of oxygen into the $\mathrm{S}$-atom of the molecule of DBT.

\section{REFERENCES}

- Arellano U, Wang JA, Timko MT., 2014, Oxidative removal of dibenzothiophene in a biphasic system using sol-gel $\mathrm{Fe}-\mathrm{TiO}_{2}$ catalysts and $\mathrm{H}_{2} \mathrm{O}_{2}$ promoted with acetic acid, Fuel; 126:16-25.

- Babich, IV, Moulijin, JA. , 2003, Science and technology of novel processes for deep desulfurization of oil refinery streams: a review, Fuel; 82:607-31.

- Cui S, Ma F, Wang Y., 2007, Oxidative desulfurization of model diesel oil over Ti-containing molecular sieves using hydrogen peroxide, React Kinet Catal Lett; 92:155-63.

- Huang D, Wang YJ, Yang LM, Luo GS., 2006, Direct synthesis of mesoporous $\mathrm{TiO}_{2}$ modified with phosphotungstic acid under template-free condition, Microporous Mesoporous Mater;96:301-6.

- Jin CZ, Li G, Wang XS, Wang Y, Zhao LX, Sun DW., 2008, A titanium containing micro/mesoporous composite and its catalytic performance in oxidative desulfurization, Micropor Mesopor Mater; 111:236-42. 


\section{Number 11 Volume 24 November $2018 \quad$ Journal of Engineering}

- Kong LY, Li G, Wang XS., 2004, Mild oxidation of thiophene over $\mathrm{TS}-1 / \mathrm{H}_{2} \mathrm{O}_{2}$, Catal Today; 93-5:341-5.

- Lorencon E, Alves DCB, Krambrock K, Avila ES, Resende RR, Ferlauto AS, 2014, Oxidative desulfurization of dibenzothiophene over titanate nanotubes, Fuel; 132:53-61.

- Lorencon E, Alves DCB, Krambrock K., 2014, Oxidative desulfurization of dibenzothiophene over titanate nanotubes, Fuel; 132:53-61.

- Lv Q, Li G, Sun HY., 2014, Synthesis of hierarchical TS-1 with convenient separation and the application for the oxidative desulfurization of bulky and small reactants, Fuel; 130:705.

- Meman, NM, Pourkhalil, M, Rashidi, A, ZareNezhad, B. Synthesis, 2014, characterization and operation of a functionalized multi-walled CNT supported MnOx nanocatalyst for deep oxidative desulfurization of sour petroleum fractions, J Ind Eng Chem; 20:4054-8.

- Ramos-Luna MA, Cedeno-Caero L., 2011, Effect of sulfates and reduced-vanadium species on oxidative desulfurization (ODS) with $\mathrm{V}_{2} \mathrm{O}_{5} / \mathrm{TiO}_{2}$ catalysts, Ind Eng Chem Res;50:2641-9.

- Shen C, Wang YJ, Xu JH, Luo GS., 2015, Oxidative desulfurization of DBT with $\mathrm{H}_{2} \mathrm{O}_{2}$ catalysed by TiO2/porous glass, Green Chem, http://dx.doi.org/10.1039/c5gc01653c.

- Yan X-M, Mei P, Xiong L.,2013, Mesoporous titania-silica-polyoxometalate nanocomposite materials for catalytic oxidation desulfurization of fuel oil, Catal Sci Technol;3:1985-92.

- Yang LN, Li J, Yuan XD, Shen J, Qi YT., 2007, One step non-hydrodesulfurization of fuel oil: Catalyzed oxidation adsorption desulfurization over HPWA-SBA-15, J Mol Catal A Chem; 262(1-2):114-8.

- Yang S-T, Jeong K-E, Jeong S-Y., 2012, Synthesis of mesoporous Ts-1 using a hybrid SiO2TiO2 xerogel for catalytic oxidative desulfurization, Mater Res Bull; 47:4398-402.

- Yazu, K., Yamamoto, Y., Furuya, T., Miki, k., Ukegawa, K., 2001, Oxidative of Dibenzothiophene in an Organic Biphasic System and its Application to Oxidation Desulfurization of Light Oil, Energy. Fuel. No.15, pp. 1535.

- Zhang W, Zhang H, Xiao J, Zhao ZX, Yu MX, Li Z., 2014, Carbon nanotube catalysts for oxidative desulfurization of a model diesel fuel using molecular oxygen, Green Chem; 16:211-20.

- Zhao DS, Wang JL, Zhou EP., 2007, Oxidative desulfurization of diesel fuel using a Bronsted acid room temperature ionic liquid in the presence of $\mathrm{H}_{2} \mathrm{O}_{2}$, Green Chem;9:121922. 


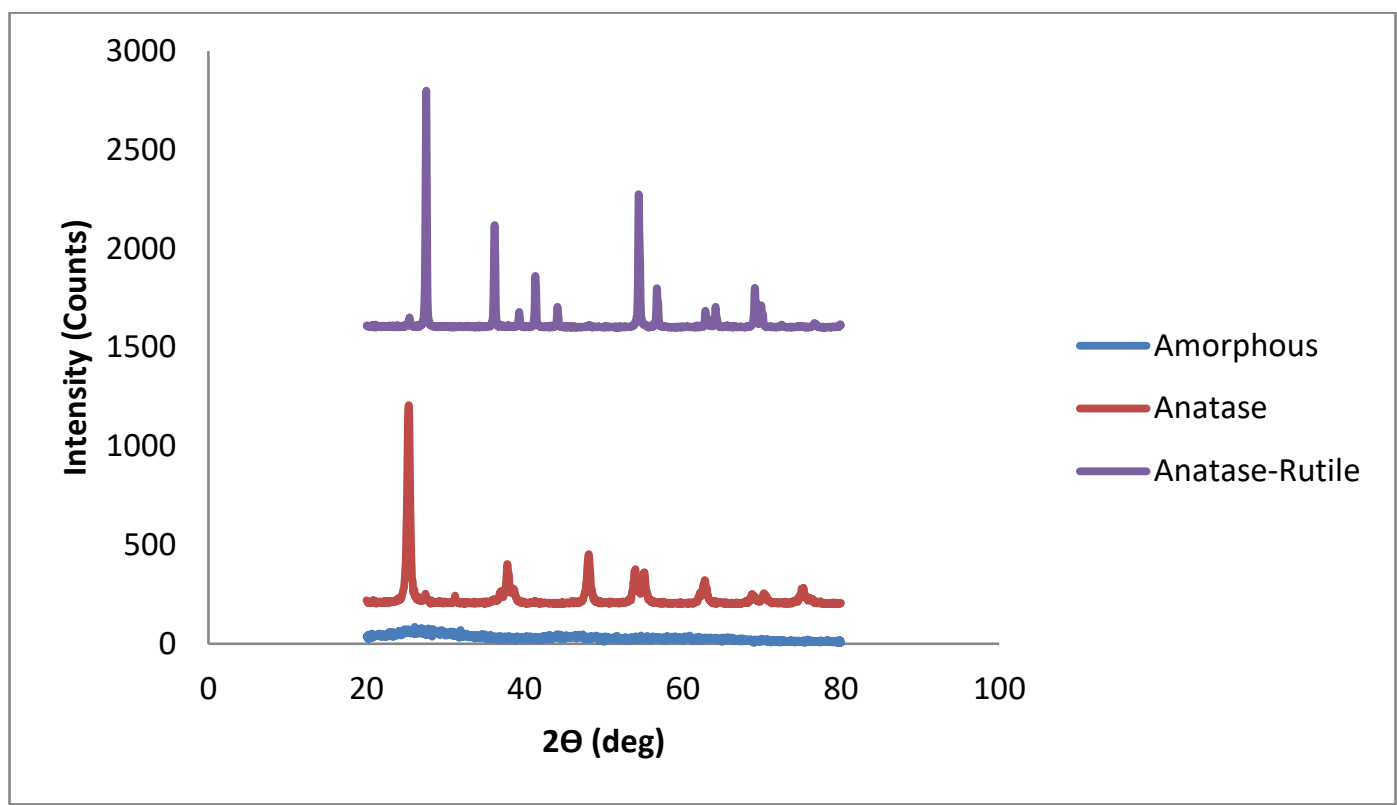

Figure 1. X-ray powder diffraction patterns of $\mathrm{TiO}_{2}$ calcined under different temperatures.

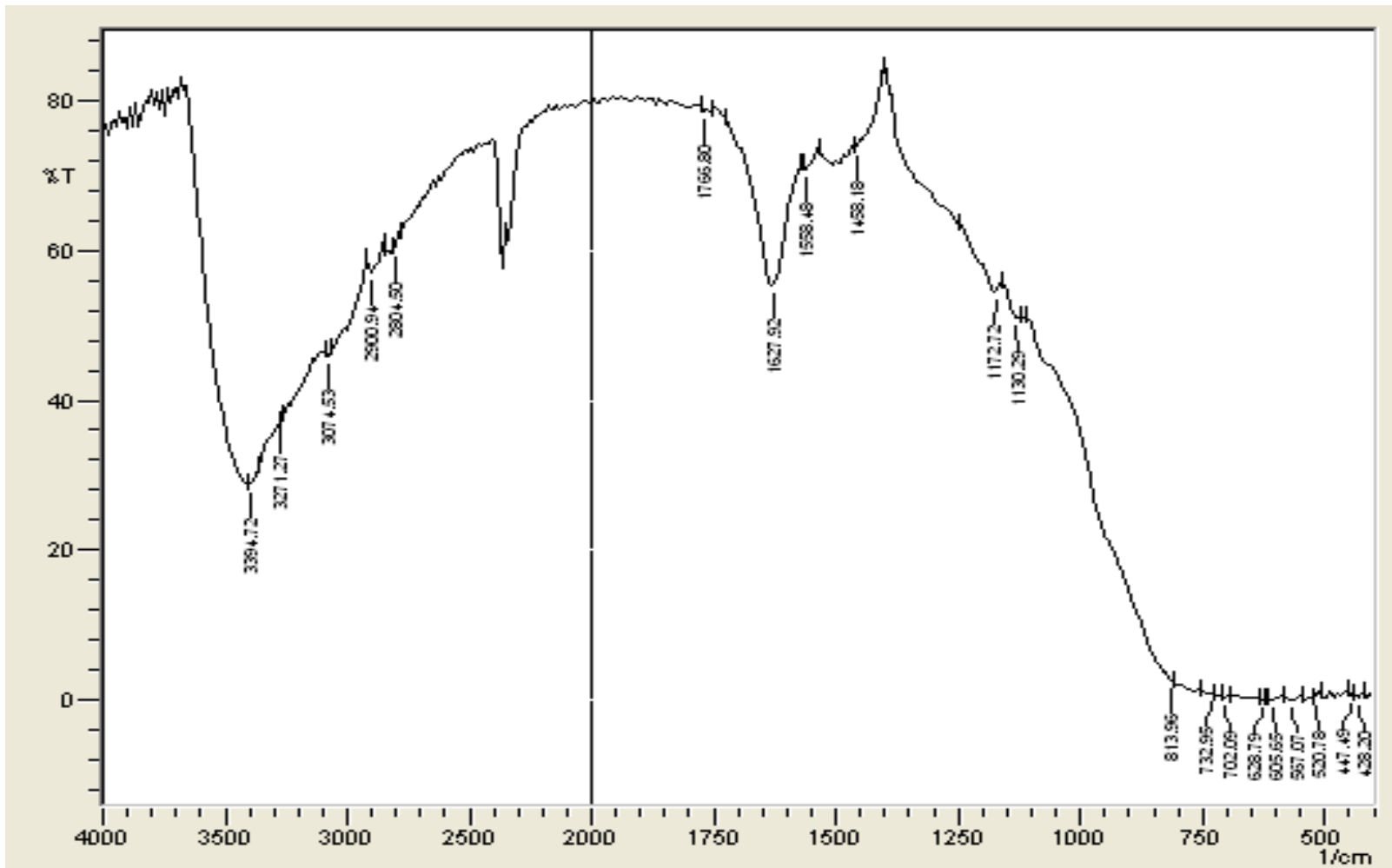

Figure 2. FTIR-spectra of the nano titanium dioxide prepared using phosphotungstic acid and STAB. 


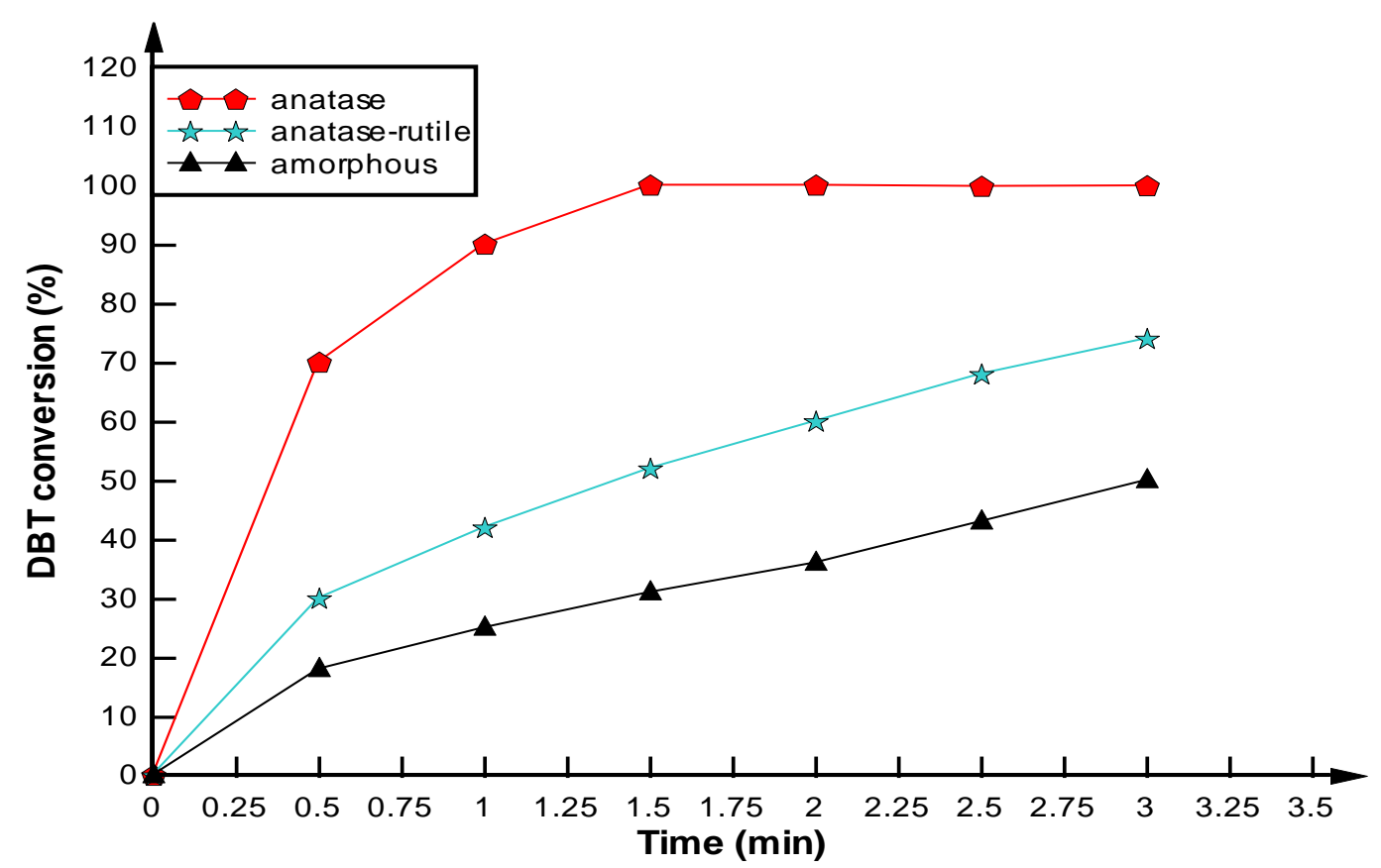

Figure 3. The catalytic oxidation of DBT prepared Conditions: $300 \mathrm{ppm}$ DBT in octane, $70^{\circ} \mathrm{C}$, the molar ratio of $\mathrm{H}_{2} \mathrm{O}_{2}$ to DBT: $10: 1,0.3 \mathrm{~g}$ of $\mathrm{TiO}_{2}$.

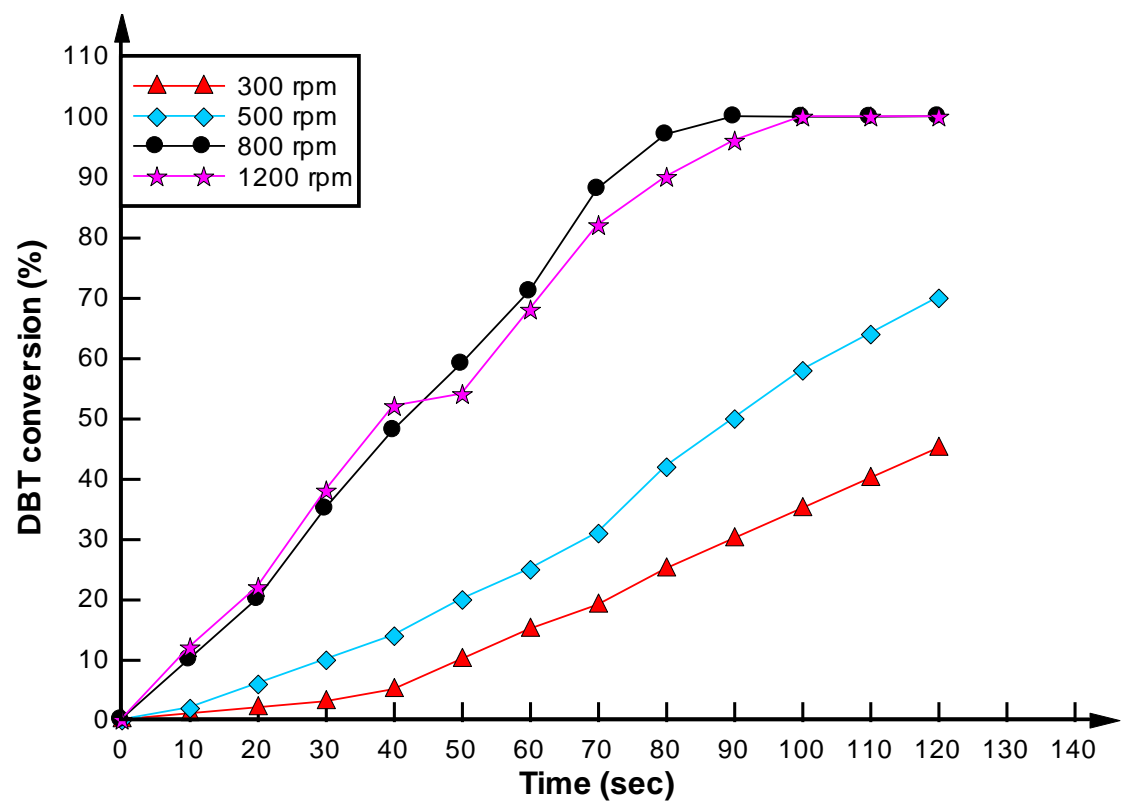

Figure 4. Effect of stirring rate on conversion: initial DBT concentration: 300 ppm; reaction temperature:; $70^{\circ} \mathrm{C}$ molar ratio of $\mathrm{H}_{2} \mathrm{O}_{2}$ to DBT: 10:1; $0.3 \mathrm{~g}$ of $\mathrm{TiO}_{2}$. 


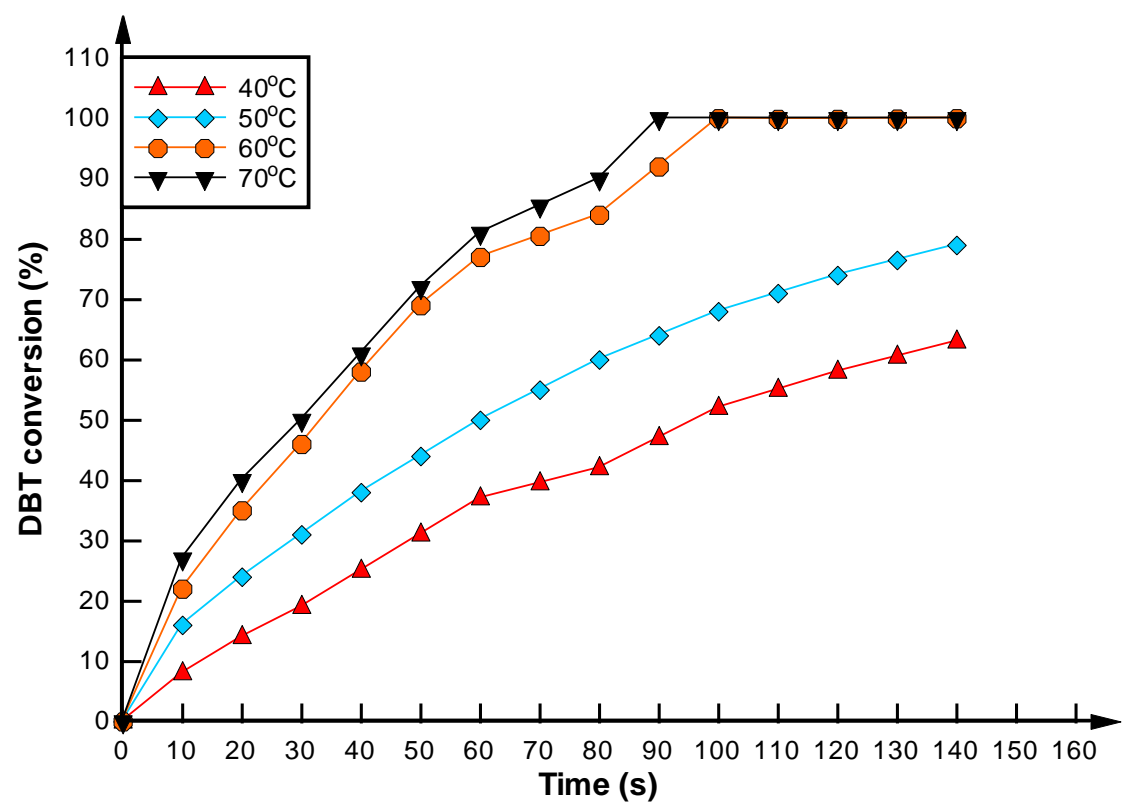

Figure 5. Effect of temperature on conversion: initial DBT concentration: 300 ppm; molar ratio of $\mathrm{H}_{2} \mathrm{O}_{2}$ to DBT: 10:1; stirring rate: $800 \mathrm{rpm} ; 0.3 \mathrm{~g}$ of $\mathrm{TiO}_{2}$.

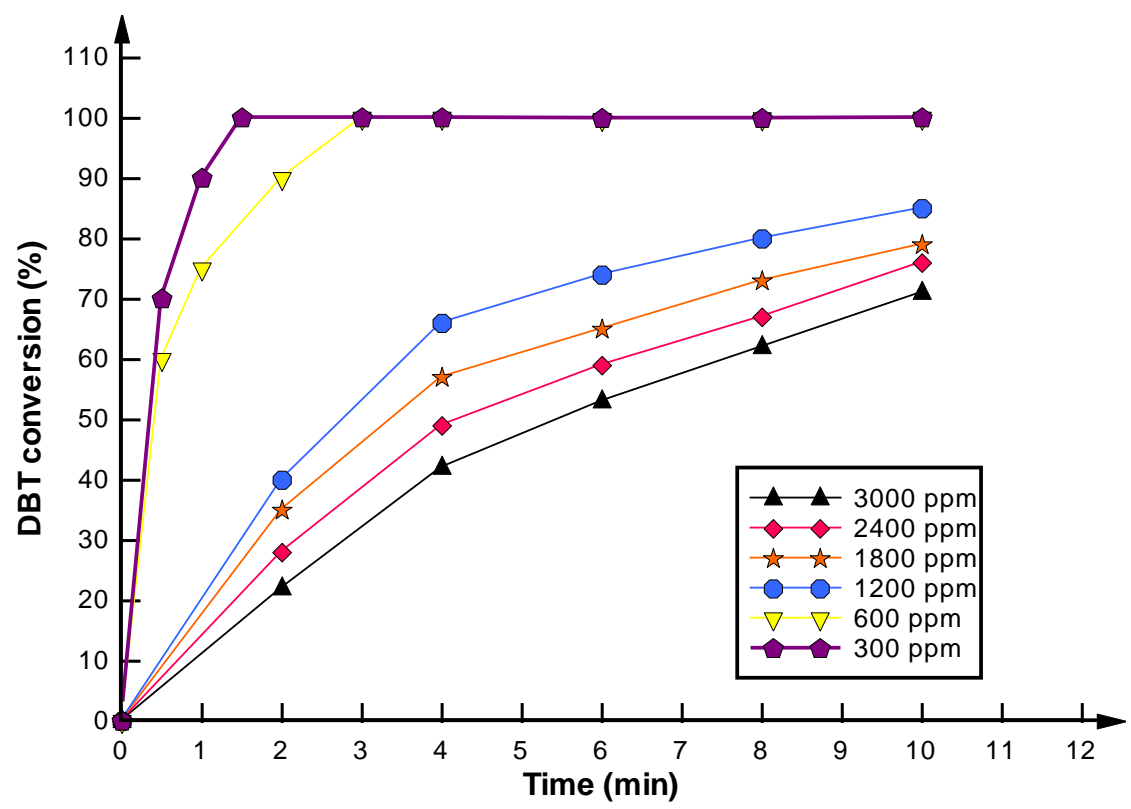

Figure 6. Effect of the initial concentration on the conversion of DBT. Conditions: $70^{\circ} \mathrm{C}$, molar ratio of $\mathrm{H}_{2} \mathrm{O}_{2}$ to DBT: 10:1, $0.3 \mathrm{~g}$ of $\mathrm{TiO}_{2}$. 


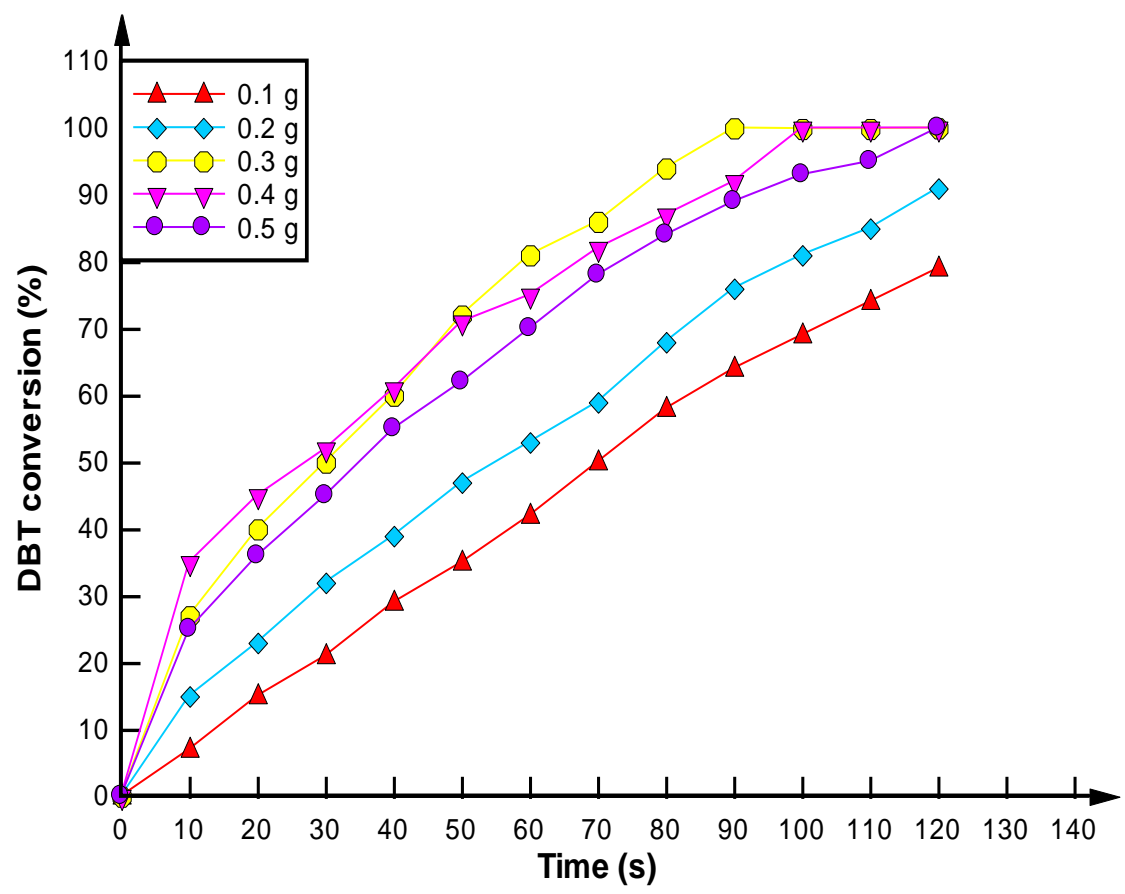

Figure 7. Effect of catalyst amount on conversion: initial DBT concentration: 300 ppm; reaction temperature:; $70^{\circ} \mathrm{C}$ molar ratio of $\mathrm{H}_{2} \mathrm{O}_{2}$ to DBT: 10:1; stirring rate: $800 \mathrm{rpm}$.

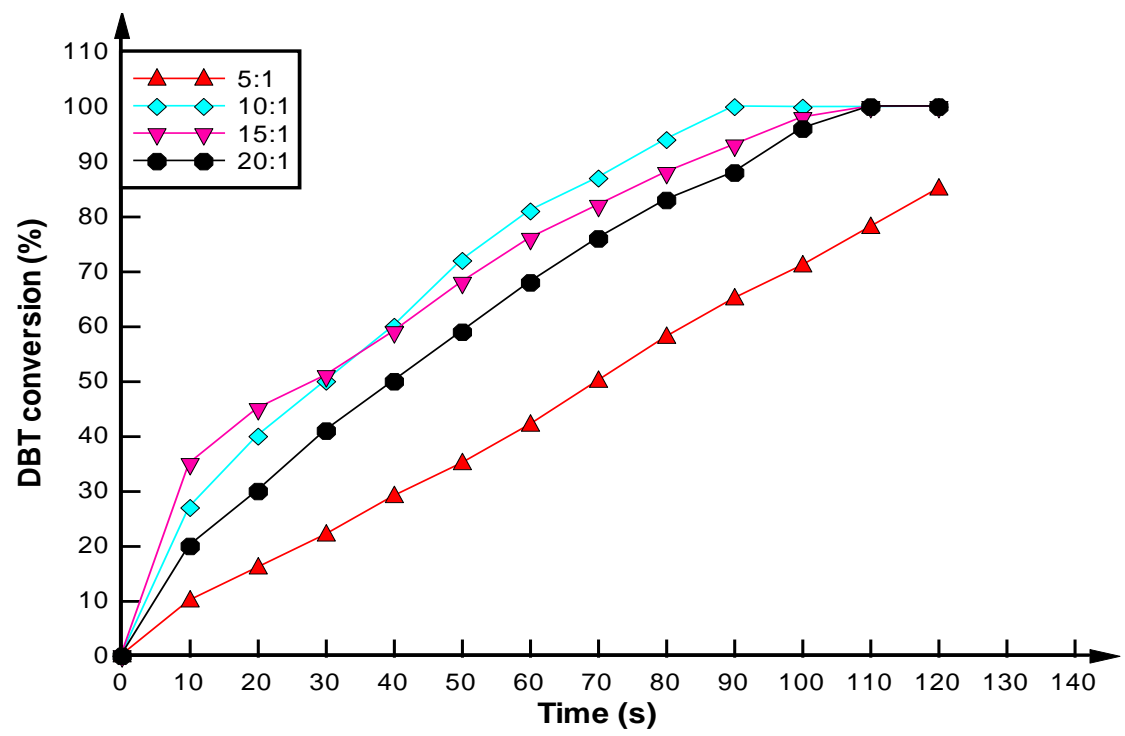

Figure 8. Effect of oxidant amount on conversion: initial DBT concentration: 300 ppm; reaction temperature: $70^{\circ} \mathrm{C}$; stirring rate: $800 \mathrm{rpm} ; 0.3 \mathrm{~g}$ of $\mathrm{TiO}_{2}$. 
Table 1. BET results of different $\mathrm{TiO}_{2}$ crystalline forms

\begin{tabular}{|l|l|l|}
\hline $\begin{array}{l}\text { Crystalline forms of } \\
\mathrm{TiO}_{2}\end{array}$ & Surface area $\left(\mathrm{m}^{2} / \mathrm{g}\right)$ & Total pore volume $\left(\mathrm{cm}^{3} / \mathrm{g}\right)$ \\
\hline Amorphous & 1183 & 0.51 \\
\hline Anatase & 423.5 & 0.24 \\
\hline Anatase-rutile & 284.2 & 0.12 \\
\hline
\end{tabular}

Table 2. The chemical composition of synthesized nano $\mathrm{TiO}_{2}$ by XRF

\begin{tabular}{|c|c|c|}
\hline Symbol & Element & Wt\% \\
\hline $\mathrm{Ti}$ & Titanium & 41.88 \\
\hline $\mathrm{W}$ & Tungsten & 11.45 \\
\hline $\mathrm{P}$ & phosphorus & 0.0013 \\
\hline
\end{tabular}

Table 3. Properties of the calcined $\mathrm{TiO}_{2}$ prepared with and without STAB

\begin{tabular}{|c|c|c|}
\hline & Surface area $\left(\mathrm{m}^{2} / \mathrm{g}\right)$ & Total pore volume $\left(\mathrm{cm}^{3} / \mathrm{g}\right)$ \\
\hline With STAB & 423.5 & 0.456 \\
\hline Without STAB & 312 & 0.278 \\
\hline
\end{tabular}

